\title{
Evaluation of the effects of donepezil in psychotic disorders using Swiss albino mice
}

\author{
Hemant Tanwani ${ }^{1}$, Ritesh Churihar ${ }^{2 *}$, Sameer Pandit ${ }^{1}$
}

\author{
${ }^{1}$ Department of Pharmacology, MGM Medical College, Indore, Madhya Pradesh, India \\ ${ }^{2}$ Department of Pharmacology, Govt. Medical College, Ratlam, Madhya Pradesh, India
}

Received: 27 January 2020

Accepted: 10 February 2020

\section{*Correspondence:}

Dr. Ritesh Churihar,

Email: dr.riteshchurihar@gmail.com

Copyright: $@$ the author(s), publisher and licensee Medip Academy. This is an open-access article distributed under the terms of the Creative Commons Attribution Non-Commercial License, which permits unrestricted non-commercial use, distribution, and reproduction in any medium, provided the original work is properly cited.

\begin{abstract}
Background: Schizophrenia as a psychotic disorder is currently treated by various antipsychotic drugs. A large group of patients still remain resistant to the treatment and present in the form of residual cognitive deficits. Donepezil has been advocated at various conferences and seminars for using it in schizophrenia patients. Donepezil is currently approved drug for Alzheimer's disease to improve cognition. Hence, we have tried to assess its role for psychotic models induced by methylphenidate in mice.

Methods: Methylphenidate $5 \mathrm{mg} / \mathrm{kg}$ was given by intraperitoneal (i.p) route to induce psychosis in Swiss albino mice $(\mathrm{n}=6)$. Donepezil was given alone in a dose of $1 \mathrm{mg} / \mathrm{kg}$ and in combination with low dose haloperidol $0.1 \mathrm{mg} / \mathrm{kg}$ and groups were compared with haloperidol $0.2 \mathrm{mg} / \mathrm{kg}$. Activity of donepezil was also assessed on the haloperidol induced catalepsy test. Statistical analysis was done with ANOVA followed by Bonferroni's test.

Results: Methylphenidate successfully induced characteristic stereotypy behaviour in mice similar to amphetamine. Both donepezil $1 \mathrm{mg} / \mathrm{kg}$ and haloperidol $0.2 \mathrm{mg} / \mathrm{kg}$ showed significant reduction in stereotypy behaviour and there was no statistically significant difference between the two $(\mathrm{p}<0.05)$. Effects with donepezil were only slightly inferior to standard while it's combination $(1 \mathrm{mg} / \mathrm{kg}$ with haloperidol $0.1 \mathrm{mg} / \mathrm{kg}$ ) showed comparable results with the standard haloperidol. Donepezil had only marginally enhanced potential to induce catatonia which was statistically insignificant $(\mathrm{p}>0.05)$.

Conclusions: Methylphenidate can be used successfully to induce psychosis in animals and donepezil may be a promising and potentially useful drug as add on therapy to routine antipsychotics.
\end{abstract}

Keywords: Donepezil, Methylphenidate, Haloperidol, Stereotypy, Albino mice

\section{INTRODUCTION}

Psychosis is classified as a symptom complex of mental illnesses which is mainly characterized by a loss of touch with the reality. Common psychotic disorders include mood disorders (major depression or mania) with psychotic features, substance induced psychosis, dementia or delirium with psychotic features, delusional disorders, schizo-affective disorders and schizophrenia.
Schizophrenia has a prevalence of $1 \%$ in the world and is considered the prototype disorder for understanding the phenomenon of psychosis and the impact of antipsychotic treatment. ${ }^{1}$

Schizophrenia is characterized by disorganized thoughts (cognition), actions (conation) and behaviour (effect). It mainly presents with positive, negative and cognitive symptoms. Positive symptoms-patients may have 
delusions, hallucinations (generally auditory), combativeness (aggression) or suspicion. Negative ones include- anhedonia, avolition, ambitendency, affect flattening and slowness of activity while lastly cognitive defects like disorganized thinking, reasoning and memory.

Current therapy for psychotic disorders is either by the use of typical antipsychotic drugs (e.g. haloperidol, chlorpromazine and thioridazine etc) or atypical ones (e.g. olanzapine, risperidone and clozapine etc.). Besides the various adverse effects seen with typical ones, many patients have still persistence of residual symptoms (to the extent of $60 \%$ with typical group, even with worsening of cognition and secondary depression which are only partially improved by atypical ones (cognitive defects may still remain up to $30 \%$ ) in addition to positive and negative symptoms. ${ }^{2}$ Hence a constant search is on for newer drugs which can be useful in above cognitive features too. So, we planned our study by using an anticholinesterase drug like donepezil, which is currently US FDA approved for Alzheimer's disease. Donepezil is used as an off labelled drug for bipolar disorders too. There is genetic similarity between the bipolar disorders and schizophrenia. The off springs of patients of schizophrenia patients are also found to have a high frequency of bipolar mood disorders. ${ }^{3}$ Few of the gene pair defects are associated with higher familial inheritance of above disorders: 1) a balanced reciprocal translocation between $1 \mathrm{q} 42$ and $11 \mathrm{q} 14.3,2$ ) there is associated between 1.5 mega base deletion of $22 \mathrm{q} 11$ and schizophrenia. It is associated with velo cardio facial syndrome. $^{4,5}$

Amphetamine is classically used as a model to induce psychosis and evaluate the antipsychotic activity in animals for new potential drugs. It works by stimulating of postsynaptic striatal fibres and mesolimbic dopamine receptors by its release. We have tried to use methylphenidate as an alternative to induce psychosis due to its similar CNS stimulant nature and pharmacological actions. $^{6-9}$ It has been shown preliminary to induce stereotype in animals. Based on these findings, it was planned to induce psychosis in albino mice and to evaluate the antipsychotic activity of donepezil alone and in combination with low dose haloperidol. The activity of donepezil was also seen on haloperidol induced catatonia since enhanced cholinergic activity itself can theoretically aggravate extra-pyramidal potential and currently centrally acting anticholinergics like biperidin and trihexiphenidyl are used to treat above symptoms.

\section{METHODS}

\section{Drugs and chemicals}

Injection Serenace (haloperidol $5 \mathrm{mg} / \mathrm{ml}$, RPG LIFE, India), Tab addwise (methylphenidate-10 mg-Sun pharma, India), Tab Alzil (donepezil $5 \mathrm{mg}$, Intas pharma,
India). The drugs were purchased from the companies through their authorized representatives.

\section{Animals}

Adult Swiss albino mice (25-30 g) of either sex were procured from the central animal house, M.G.M. medical college, Indore and acclimatized for a period of 7 days, 12 hours cycles of light and dark, at room temperature of $\left(25 \pm 2^{\circ} \mathrm{C}\right)$ and $(50 \pm 15 \%)$ relative humidity. They were housed in a standard cage and maintained on standard pellets and water at Librium. The animals were used as per standard animal care guidelines. The study was done in the department of pharmacology, M.G.M. Medical College, Indore and the study protocol were approved by the institutional animals' ethics committee (IAEC) registered with CPCSEA (Reg No 709).

\section{Methylphenidate induced psychosis}

Animals were kept fasting after midnight and only water was allowed in the morning. The psychosis was induced in mice by using methylphenidate in dose of $5 \mathrm{mg} / \mathrm{kg}$ by suspending in $2 \%$ gum acacia. Methylphenidate, by stimulating dopaminergic receptors in mesolimbic system, can stimulate a stereotype behavior (purposeless, repeated and abnormal facial movements like a gnawing, paw leaking and sniffing) in animals. ${ }^{6}$ This behavior is presently considered equivalent to psychotic features and used for evaluating the antipsychotic potential of new drugs. ${ }^{7}$ Mice of either sex were selected and they were randomly divided into 6 groups $(n=6)$.

Group I animals received gum Acacia 2\% $0.2 \mathrm{ml}$ and considered as control group. Group II animals received methylphenidate alone $(5 \mathrm{mg} / \mathrm{kg})$. Group III mice methylphenidate $(5 \mathrm{mg} / \mathrm{kg})$ and haloperidol $(0.2 \mathrm{mg} / \mathrm{kg})$. Animals in group IV received methylphenidate $(5 \mathrm{mg} / \mathrm{kg})$ and haloperidol $(0.1 \mathrm{mg} / \mathrm{kg})$. Group $\mathrm{V}$ mice received methylphenidate $(5 \mathrm{mg} / \mathrm{kg})$ and donepezil $(1 \mathrm{mg} / \mathrm{kg})$ and mice in group VI received methylphenidate $(5 \mathrm{mg} / \mathrm{kg})$, donepezil (1 mg/kg), and haloperidol $(0.1 \mathrm{mg} / \mathrm{kg})$.

All the drugs were given by intraperitoneal route (i.p). The drugs donepezil and haloperidol were given half an hour before methylphenidate injection (pre-treatment) and animals placed in stainless steel cages and number of stereotype movements were recorded for 10 minutes after half an hour of methylphenidate injection. Stereotype movements were characterized by continuous sniffing, licking or compulsive gnawing. An animal was considered to be protected if stereotype behavior was significantly reduced or abolished.

\section{Haloperidol induced catatonia}

Principle-phenothiazines (chlorpromazine as prototype) and butyrophenone (e.g. haloperidatol) group of typical antipsychotic drugs is known to produce extra pyramidal symptoms like akinesia, tremors and rigidity 
(parkinsonian features) in humans. ${ }^{1}$ These symptoms are due to blockage of dopamine receptors, causing imbalance of its ratio with acetylcholine at basal ganglion. Therefore, above drugs are used in animals to induce catatonia symptoms and to evaluate the extrapyramidal potential of experimental drugs. Normal dose of haloperidol for inducing catatonia (sustained rigidity) is $2 \mathrm{mg} / \mathrm{kg}$ but here $1 \mathrm{mg} / \mathrm{kg}$ was used so that it could elicit a moderate degree of catatonia and thus elicit the partial attenuation or the potentiation of the response. Catalepsy was induced by haloperidol $1 \mathrm{mg} / \mathrm{kg}$ IP and assessed at every 30 minutes till the end of 120 minutes. It was assessed for the time for which an animal maintained an imposed position with both front limbs extended and resting on a $4 \mathrm{~cm}$ high wooden bar. The end point of catalepsy was considered when the animal moved all of his limbs or two front legs in a head rotating exploratory manner. A cut-off point of $1100 \mathrm{Sec}$ was applied for a single response. In our experiment we counted the number of animals which showed the catatonia response, total responses and compared them among the different groups i.e., between group I animals receiving gum Acacia $2 \% \quad 0.2 \mathrm{ml}$, group II animals receiving haloperidol $(1 \mathrm{mg} / \mathrm{kg})$, group III animals receiving haloperidol $(1 \mathrm{mg} / \mathrm{kg})$ and trihexyphenidyl (10 $\mathrm{g} / \mathrm{kg}$ ) and group IV animals receiving haloperidol (1 $\mathrm{mg} / \mathrm{kg}$ ) and donepezil (1 $\mathrm{mg} / \mathrm{kg})$.

\section{Statistical analysis}

Data were expressed as Mean \pm SEM and analysis were carried out by one-way ANOVA followed by Bonferroni's using SPSS as software version 20.0. Value of $\mathrm{p}<0.05$ was considered to be statistically significant.

\section{RESULTS}

\section{Antipsychotic activity}

In the study to use methylphenidate for induction of psychosis and evaluation of antipsychotic effects of donepezil, the methylphenidate (group II) showed the same pattern of stereotypy movements as with amphetamine when it was used to induce psychosis in rodents like gnawing, licking and sniffing and the number of movements were significantly higher than the control (group I) $(\mathrm{p}<0.05)$ where almost no abnormal movements were seen. The number of movements was significantly reduced in haloperidol $0.2 \mathrm{mg} / \mathrm{kg}$ (group II). Similarly, movements in methylphenidate and donepezil combination (group V) were markedly reduced and not significantly different from the group III $(p>0.05)$. These movements were again highly reduced in methylphenidate with donepezil and low dose haloperidol combination (group VI) $(\mathrm{p}<0.05)$. So overall there was no significant difference in stereotype movements among III, V and VI groups ( $\mathrm{p}>0.05)$. These all experimental findings highly suggest for a possible role of donepezil to control even acute features of psychosis also. Further clinical studies will be required to evaluate its potential possible role (Table 1).

\section{Catatonia potential}

In the control (group I) no catatonia movements seen, which were increased at 120 minutes in group II while in groups III, they were reduced while in the last group of haloperidol and donepezil combination (IV) they were slightly more as can be expected from its enhancing cholinergic activity in the basal ganglion (Table 2).

Table 1: Effect of donepezil on methylphenidate induced stereotypy.

\begin{tabular}{|lllll|}
\hline Group & Treatment given & Dose $(\mathrm{mg} / \mathrm{kg})$ & $\begin{array}{l}\text { Stereotypy } \\
\text { movements }\end{array}$ & Inference \\
\hline I (control) & Gum Acacia & $0.2 \mathrm{ml}$ & $1.2 \pm 0.2$ & No effect \\
\hline II & Methylphenidate & 5 & $52.5 \pm 0.35^{*}$ & Potential psychotic \\
\hline III & Methylphenidate+haloperidol & $5+0.2$ & $22.3 \pm 0.5$ & Marked antipsychotic \\
\hline IV & Methylphenidate+haloperidol & $5+0.1$ & $50.8 \pm 0.2$ & No antipsychotic activity \\
\hline V & Methylphenidate+donepezil & $5+1$ & $22.3 \pm 0.5^{* \#}$ & Potential antipsychotic \\
\hline VI & Methylphenidate+haloperidol & $5+0.1+1$ & $23.33 \pm 0.5^{* \#}$ & Potential antipschotic activity \\
\hline
\end{tabular}

Results: One-way ANOVA followed by Bon Ferroni's test; values expressed in mean \pm SEM, ${ }^{*}$ Significant stereotypy ( $<<0.05$ ), \#significant effect without difference between group $5 \& 6$ ( $>0.05)$.

Table 2: Effect of donepezil on haloperidol induced catatonia.

\begin{tabular}{|llllll|}
\hline S. no. & Treatment given & Dose $(\mathbf{m g} / \mathbf{k g})$ & \multicolumn{3}{l|}{ Mean catatonia score } \\
\hline I (control) & Gum Acacia & $0.2 \mathrm{ml}$ & $0.55 \pm 0.22$ & $45 \pm 0.32$ & $12 \pm 0.02$ \\
\hline II & Haloperidol & 1 & $16.35 \pm 2.38^{*}$ & $23.31 \pm 3.23$ & $28.45 \pm 0.33$ \\
\hline III & Haloperidol+trihexyphenidyl & $1+10$ & $12.33 \pm 1.55^{\#}$ & $13.45 \pm 1.67$ & $16.44 \pm 0.34$ \\
\hline IV & Haloperidol+donepezil & $1+1$ & $13.65 \pm 45^{\mathrm{a}}$ & $15.34 \pm 99$ & $18.22 \pm 0.79$ \\
\hline
\end{tabular}

Results: One-way ANOVA followed by Bon Ferroni's test. The values expressed in mean \pm SEM, *Significant catatonia $(\mathrm{p}<0.05)$,

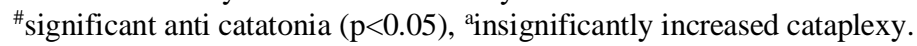




\section{DISCUSSION}

\section{Methylphenidate as a model for psychosis}

Methylphenidate is a sympathetic drug which releases dopamine from various mesolimbic system nuclei like the amygdala and hippocampus to produce psychotic behavior like purposeless stereotype movements similar to an amphetamine group of drugs. Due to narcotic act restrictions, we have used methylphenidate with equally good results. Currently methylphenidate is used for attention deficit disorders and narcolepsy. In study by Kuczenski et al and Segal et al, methylphenidate produced a dose dependent pattern of locomotion and stereotypy similar to results with amphetamine in previous studies. ${ }^{7-9}$ It is a CNS stimulant, its proposed mechanism is the release and increase of dopamine. This release is secondary to its effect on the dopamine transport mechanism which results in an increased amount of postsynaptic dopamine. ${ }^{10}$

\section{Antipsychotic potential of donepezil and its possible mechanisms}

Our results had shown that donepezil was able to control stereotype which is equivalent to clinically observed acute behavior in human. The stereotype behavior was completely abolished by donepezil, which was comparable to standard drug haloperidol $(0.2 \mathrm{mg} / \mathrm{kg})$ group. The stereotype was completely abolished, even there was no statistically significant difference between the above two groups.

The probable mechanism of donepezil (acting via acetylcholine may be similar to glutamate, which (at prefrontal cortex-mesocortex) inhibits the levels of mesolimbic dopamine via inhibition of cortical-fugal fibres carrying glutaminergic neurons.

Another possible mechanism may be of a reciprocal relation between (prefrontal) mesocortex and mesolimbic system among different neurotransmitters like dopamine and acetylcholine, similar to different nuclei of basal ganglion. High levels of acetylcholine through mesocortical fibres may directly inhibit levels of dopamine at mesolimbic system to reduce dopamine levels, while by its own at prefrontal cortex may be improving cognition.

\section{Evidences of low cholinergic activity responsible for psychosis}

Well established cholinergic neuronal degeneration is seen in Alzheimer's disease where there is loss of memory, defective reasoning and thought process patterns leading to psychotic features. ${ }^{1}$ Toxic doses of anticholinergic in poisoning (belladonna) are associated with symptoms of delirium-acute deranged cognition and toxic confusional state. ${ }^{11-12}$ Typical antipsychotics with strong anticholinergic property like thioridazine are less potent antipsychotics, rather they can even worsen the negative and cognitive symptoms. Still centrally acting anticholinergic like trihexyphenidyl are often added to antipsychotics to prevent extra pyramidal symptoms. They are discouraged to use simultaneously nowadays, unless until required to correct extrapyramidal symptoms. They themselves produce distressing anticholinergic symptoms like dry mouth, blurring of vision and urinary retention, etc produce dullness, can aggravate negative and cognitive deficits as above. ${ }^{12}$ Latest reports of donepezil in autistic disorders which are considered at various classifications to be childhood psychotic disorders. ${ }^{13}$ Clozapinean atypical drug, used to treat resistant schizophrenia patients has been able clinically to better control cognitive defects. ${ }^{14}$ By genetic studies, it has been found to have more affinity for a subtype of nicotinic receptors represented as $\mathrm{N}_{7}$ alpha4. Schizophrenics are found to smoke at twice the rate as compared to the general population, they may be inhaled nicotine to stimulate the cholinergic system for temporary relief from negative and cognitive deficits. It is also possible that few patients with schizophrenia who respond to donepezil may actually represent a genetic subgroup having deficient cholinergic activity among one of the aetiology of schizophrenia. Our results are matched to those of preclinical studies done by Gabbard et al. ${ }^{15}$

\section{Possible role in tardive dyskinesias}

Typical drugs are associated with tardive dyskinesias which are problematic for the patients and attendants in the form of purposeless movements of head, limbs, neck, tongue (like bird catching movements) and sometimes whole body leading to abnormal rotating and darting movements.

The aetio pathogenesis involves prolonged therapymainly with typical antipsychotics (less frequent with atypical ones) having anti dopaminergic therapy with consequently enhanced receptor super sensitivity over a period of time (generally over 6 months) of chronic treatment. Often the treatment of tardive movements is unsatisfactory. To correct them: 1) either the dose of antipsychotic is reduced, leading to worsening of psychosis or 2) the dose is increased which further leads to deterioration of above symptoms. ${ }^{11}$ The current treatment is unsatisfactory, still they are treated with benzodiazepines or beta blockers.

The addition of donepezil on theoretical grounds can normalize the acetylcholine and dopamine ratio at basal ganglion, to lower the chances of tardive dyskinesias. It has been tried in various research works worldwide and overall, they have given encouraging results. It has also been used to treat levodopa induced dyskinesias. We can recommend donepezil as add on therapy to lower the frequency of tardive diskinesias on long term. ${ }^{16}$

\section{CONCLUSION}

It can be useful as an add on therapy to rapidly control acute psychotic symptoms. It can rapidly improve 
cognitive deficits and motor activity of its own. It can improve the insight, self-esteem and morale to help the overall disease process. It has been found to stimulate the release of dopamine and serotonin at preferential mesocortex to correct depression too, partly improving negative symptoms too. Further studies are needed to support our results and its utility.

\section{ACKNOWLEDGEMENTS}

The authors are thankful to acknowledge staff of department of pharmacology, M.G.M. medical college, Indore, (M.P.) for providing animals and support during experiments.

Funding: No funding sources Conflict of interest: None declared

Ethical approval: The study was approved by the Institutional Animal Ethics Committee

\section{REFERENCES}

1. Baldessarani RJ, Tarzai FI, Brunton L, Lazo JS, Parker KL. Drug therapy of psychosis and mania. Goodman and Gilman's, The Pharmacological Basis of Therapeutics, 11th ed. New York, NY: McGrawHill. 2006: 461-480.

2. Sadock BJ, Sadock VA. Schizophrenia, Synopsis of psychiatry: Behavioral Sciences or clinical Psychiatry, 10th ed. Philadelphia, PA: Lippincott Williams and Wilkins. 2007: 410-520.

3. Moller HJ. Bipolar disorder and schizophrenia: distinct illnesses or a continuum. J Clin Psychiatry. 2003;64(6):23-7.

4. Neill DB, Grant LD, Grossman SP. Selective potentiation oflocomotor effects of amphetamine by midbrain raphe lesions. Physiol Behav. 1972;9(4):655-57.

5. Solanki RK, Singh P, Munshi D. Current perspectives in the treatment of resistant schizophrenia. Indian J Psychiatr. 2009;51:254-60.

6. Vogel HG. Inhibition of amphetamine stereotypy in rats. Chapter E.5.3.2. Drug Discovery and Evaluation. Pharmacological assays. 2nd ed. Heidelberg, Germany: Springer; 2002: 535-537.
7. Westfall TC, Westfall DP, Brunton L, Chabner B, Knollman B. Adrenergic agonists and antagonists. Goodman and Gilman's The Pharmacological Basis of Therapeutics. 12th ed. New York, NY: McGrawHill; 2011: 299.

8. Kuczenski R, Segal DS. Effects of Methyiphenidate on Extracellular Dopamine, Serotonin, and Norepinephrine: Comparison with Amphetamine. J. Neurochem. 1997;68(5):2032-7.

9. Morton WA, Stockton GG. Methylphenidate Abuse and Psychiatric Side Effects. Prim Care Companion J Clin Psychiatry. 2000;2(5):159-64.

10. Balcioglu A, Ren JQ, Carthy MD, Spencer TJ, Biederman J, Bhide PG. Plasma and brain concentrations of oral therapeutic doses of methylphenidate and their impact on brain monoamine content in mice. Neuropharmacology. 2009;57(7-8):687-93.

11. Nyati P. Psychopharmacogy. In: Pharmacology SEED, 2nd ed. New Delhi: Globalmedik; 2011: 7579.

12. Garg PD. In: adult clinical psychiatry, Concise psychiatry for undergraduates. 1 st ed. Sirmor, India: Arya Publishing Company; 2006: 79-80.

13. Handen BL, Taylor J, Tumuluru R. Psychopharmacological treatment of ADHD symptoms in children with autism spectrum disorder. Int J Adolesc Med Health. 2011;23:167-73.

14. Yarlagadda A, Clayton AH. Role of cholinergic system and calcium synchronization in schizophrenia. Psychiatry (Edgmont). 2009;6:37-41.

15. Gabbard GL. In: Treatment of psychiatric disorders by Gabbard, DSM-5th edition. Washington, NY: Amer psychiatric Pub; 2014: 200-204.

16. Seltzer B. Donepezil: an update. Expert Opin Pharmacother. 2007;8(7):1011-23.

Cite this article as: Tanwani $\mathrm{H}$, Churihar $\mathrm{R}$, Pandit S. Evaluation of the effects of donepezil in psychotic disorders using Swiss albino mice. Int J Basic Clin Pharmacol 2020;9:533-7. 